\title{
A Novel Follicular Unit Excision Device for All-Purpose Hair Graft Harvesting
}

\author{
Sanusi Umar (iD ${ }^{1-3}$ \\ Boudine Lohlun (1D) \\ Tayfun Ogozuglu (iD ${ }^{5}$ \\ Marissa J Carter (DD ${ }^{6}$ \\ 'Department of Medicine, Dermatology \\ Division, University of California, Los \\ Angeles, CA, USA; ${ }^{2}$ Division of \\ Dermatology, Harbor-UCLA Medical \\ Center, Torrance, CA, USA; ${ }^{3}$ Dr. U Hair \\ and Skin Clinic, Manhattan Beach, CA, \\ USA; ${ }^{4}$ HairFront Clinic, Cape Town, \\ South Africa; ${ }^{5}$ Dr. T Hair Transplant, \\ Istanbul, Turkey; ${ }^{6}$ Strategic Solutions, Inc., \\ Bozeman, MT, USA
}

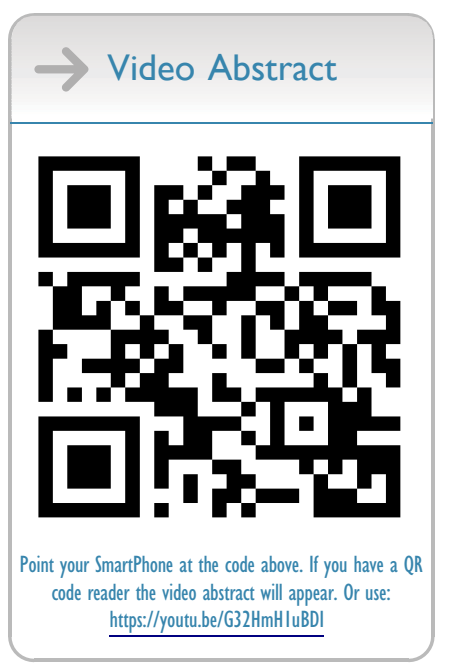

Correspondence: Sanusi Umar Dr. U Hair and Skin Clinic, 2121

N. Sepulveda Boulevard, Suite 200,

Manhattan Beach, CA, 90266, USA

$\mathrm{Tel}+|-3| 0-3 \mid 8-1500$

$\mathrm{Fax}+\mid-310-318-1590$

Email drumar@dru.com
Purpose: A challenge in follicular unit excision (FUE) is the lack of a single device that can adequately meet the requirements of a range of patient donor variables, such as hair curliness, race, body and head hair locations, and non-shaven short- and long-hair FUE. This study aimed to describe a novel FUE device developed based on skin responsiveness to serve as a single all-purpose FUE donor harvester.

Patients and Methods: We describe an all-purpose FUE device that consists of an allpurpose punch and a functionally complementing punch driver. The mechanism of action and method of use are reported. Several patients with a diversity of FUE challenges for three experienced FUE practitioners using the novel device are presented using photos and videos. The practitioners also reported their comparative experiences with using prior FUE systems in similar situations.

Results: The novel device demonstrated success in a variety of FUE scenarios without requiring specialized provider skills. The device responds to changing skin firmness and thickness, which are the primary causes of inconsistent performance in FUE devices between patients and within patients from one body/head area to another. It also minimized challenges of unpredictable hair curliness and angles by its innate ability to self-navigate the subsurface course of hair follicles, to which the FUE practitioner is typically blinded.

Conclusion: We describe a novel FUE device that overcomes the challenges of previous FUE technologies and has potential applicability to a diverse range of FUE scenarios. Our experience suggests that further validation is warranted.

Keywords: follicular unit extraction, hair transplant, African American, long hair, curly hair, body hair, non-shaven

\section{Introduction}

Follicular unit excision (FUE), previously called follicular unit extraction, is currently the most popular and only minimally invasive follicle-harvesting method in hair transplantation. The term "excision" was adopted to reflect the surgical nature of the procedure. FUE is a 2-step surgical process that involves making a fullthickness circumferential incision into the skin around a follicular unit, enabling removal of a full-thickness skin graft containing an intact follicular unit bundle. FUE has advantages over follicular unit strip surgery for hair transplantation because it avoids creating a linear scar, nerve dissection, and the misalignment of the natural flow of scalp hairs. Furthermore, FUE enables the expansion of the donor supply to beard and body hair.

All FUE methods involve using a punch to cut the tissue and a punch driver that drives the punch cutting tip. The driver could be manual, whereby the operator 
manually rotates a handheld punch in a skin biopsy-type maneuver, or mechanical, where the punch is mounted on an electromechanical drill device typically adopted from existing dental drill systems. Existing FUE devices have various limitations, and to date, no single device has been able to adequately address the range of patient donor variables. Such variables include hair curliness, racial differences in skin and hair, body and head hair locations, and the growing demand for non-shaven and long hair FUE. Most devices are ineffective in harvesting hair from people of African descent ${ }^{1-3}$ or extracting follicles from various body areas. ${ }^{4}$ Additionally, they do not adequately perform when faced with changing skin and hair characteristics between and within patients from one body/head area to another. ${ }^{5,6}$ Consequently, not everyone can benefit from the advantages of FUE over other hair transplant methods. Some devices perform excellently in one type of harvest but not in others. $^{7,8}$ Therefore, practitioners often acquire various devices hoping that one of these might suit the variety of patients they encounter since no single device suits all situations. ${ }^{9}$ Other practitioners seek to develop specialized skills in using conventional FUE tools to address challenging FUE scenarios. ${ }^{10}$

To address these limitations, we report a versatile device to accommodate most FUE presentations, including head hair extraction (shaven or non-shaven) in all races, all beard and body hair extractions, and long-haired graft harvesting that does not require switching punches, the driver, or the development of specialized skill sets. We here describe the device's features and use.

\section{Patients and Methods}

\section{Ethical Statement}

All patients who underwent FUE provided written informed consent, including consent for publication, and all procedures were conducted in accordance with the Declaration of Helsinki (revised in 2013). Institutional Review Board approval was not required or sought as this study was not a prospective or systematic investigation of FUE treatment but described general principles for routine FUE practice.
The device consists of an all-purpose FUE punch mounted on a skin-responsive driver optimized at several levels when working in tandem.

\section{All-Purpose Punch}

An all-purpose punch called the Intelligent Punch Dr. U Punch i (Dr. U Devices Inc, Manhattan Beach, CA), was developed to serve all FUE scenarios (Figure 1). The punch design was optimized at multiple levels to incorporate solutions to several technical challenges known to contribute to FUE graft attrition (lost or non-viable grafts from transections, crush injuries, and complete de-sheathing), poor scarring profiles, and user experiences.

\section{Punch Cutting Axis Optimization}

As it advances into the depths of the skin, an FUE punch must cut the tissue that envelops and anchors the hair follicle to its lateral surroundings. The cylinder of scored follicle ascends into the lumen of the punch, with tissue distal to the punch tip constantly in the crosshairs of the punch cutting tip, increasing the risk of transecting and damaging the graft (Figure 2A-C). Thus, the cutting end of the all-purpose punch was flared to point the edges of the tip away from the graft axis to minimize this risk (Figure 2D-F). ${ }^{11-17}$

\section{Punch Diameter and Wound Healing Optimization}

Generally, large punches register fewer graft transections. ${ }^{5}$ The flaring of the punch (Figure 1) mitigates transection rates compared with straight punches of the same diameter. However, the diameter of the funnel-shaped rim (responsible for the first skin cut and wound size) of an ordinarily flared punch increases the diameter of the punch to exceed the diameter of the long cylinder (Figure 3A). The punch design was further optimized to impart the benefits of flaring without increasing the tip diameter beyond the perimeter of the punch's long cylinder (Figure 3B), thus avoiding an increase in wound size. This was achieved by coring out concavities from the

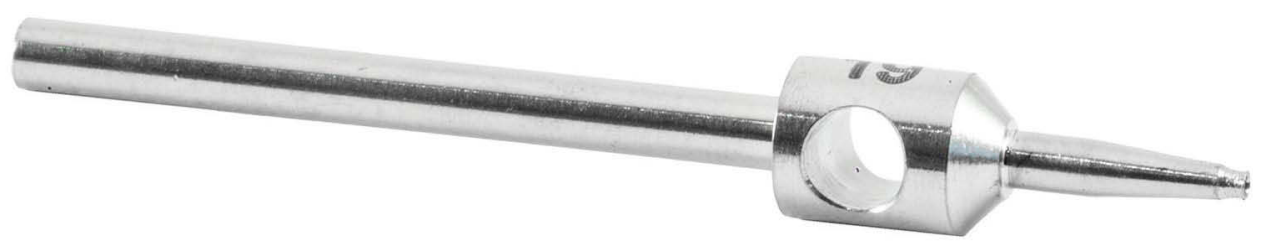

Figure I The all-purpose punch, showing the frustoconically shaped, textured cutting end and a flared cutting tip. 

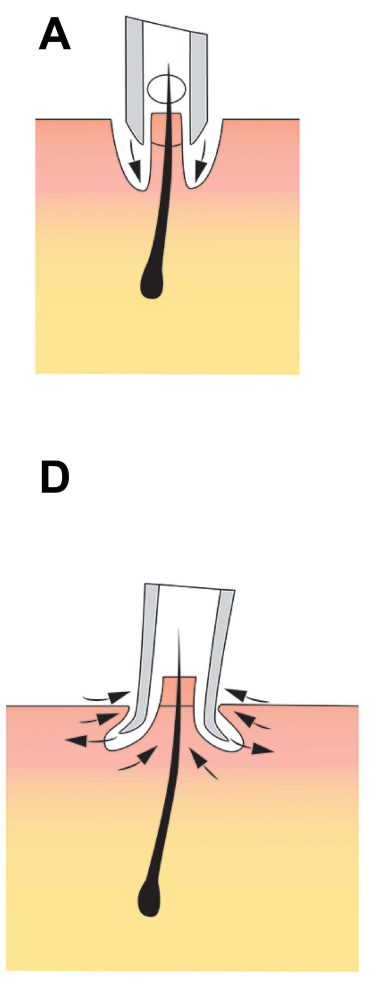

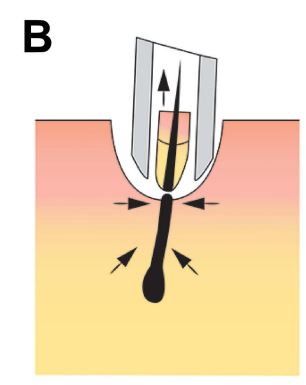

E

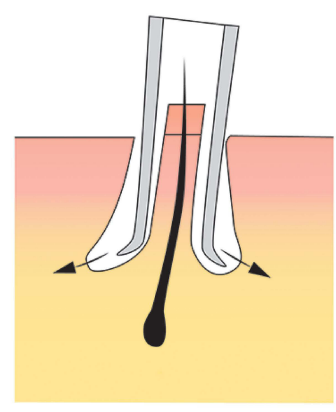

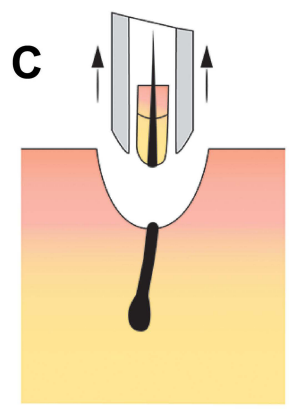

$\mathbf{F}$

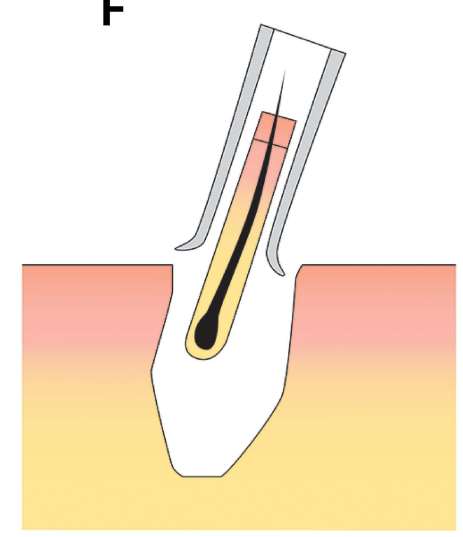

Figure 2 Patent application schematics demonstrating the advantage of a flared punch cutting tip. (A) Outer beveled punch tip shows cutting vectors directed towards the follicle; (B and $\mathbf{C})$ the outer beveled punch transects the follicle before advancing to the follicle's level (D) a flared punch with cutting vectors pointing away from the follicle $(\mathbf{E}$ and $\mathbf{F}$ ) show minimal tendency to transect grafts while reaching deeper levels of the follicle, unlike the outer beveled punch.

thickness of the outer surface of the punch end 1-2 $\mathrm{mm}$ (Figure 3A). ${ }^{11,17}$

Flaring of the device tip confers a wound-healing advantage because of the skin entry vectors of the cutting edge and the shape of the first $1-2 \mathrm{~mm}$ of the wound's edge. This creates an epidermis-to-wound edge angle that is relatively smaller. The result is a wound that heals more by primary than by secondary intention. Opposing epidermal wound edges meet mostly by wound contraction rather than exposed dermal tissue that heals mostly by secondary intention, resulting in a more prominent scar (Figure 4). ${ }^{18}$ Moreover, in studies focusing on scalp FUE, stretching the dermis by normal saline tumescence was used to achieve a similar objective. ${ }^{19}$ The wound shape and healing advantage conferred by the flaring of the punch allows for a relatively larger punch to achieve lower transection rates while still incorporating the wound healing benefits of a smaller punch. This advantage allows the use of at least one needle-gauge-size larger on the all-purpose punch to achieve a wound finish equal to or better than that conferred by a non-flared punch that is a needle-gauge-size smaller.

\section{Punch Optimization for Torsion Injury Reduction}

When a punch scores the graft and advances along the deeper portions of the graft, the proximal portion of the graft is pulled into the rotating punch's lumen (Figure 5A). Any friction between the punch's inner surface and the graft results in the punch and the intraluminal portion of the graft rotating in unison, causing the punch to be out of sync with the graft outside the punch, which is still anchored to the surrounding tissue. This results in twisting the follicle at the junction between the rotating and stationary parts, ultimately leading to transection (Figure 5B). To minimize this, the punch lumen was volumized by expanding its diameter relative to its cutting tip diameter that defines the diameter of the graft tissue entering the punch lumen. The diameter increase is progressive, starting from $1-2 \mathrm{~mm}$ of the tip to approximately $7 \mathrm{~mm}$, to define a frustoconical-shaped cylinder (Figure 5C). This design produces less friction between the punch's inner lining and the graft and minimizes torsion-induced transections. $^{16}$ 


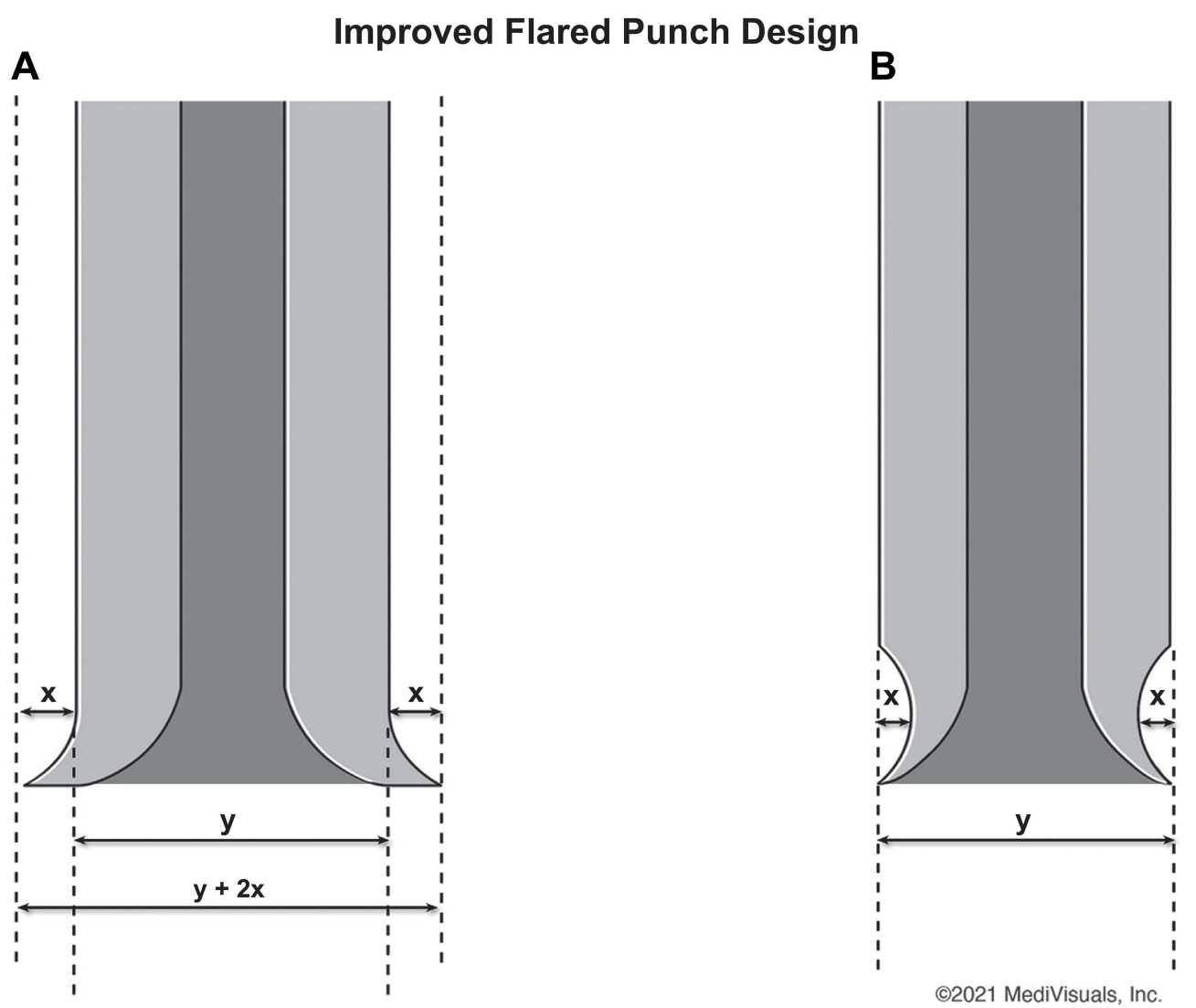

Figure 3 The diameter of an ordinarily flared punch $(\mathbf{A})$ is broader than that of the all-purpose punch forged from the same outer-diameter punch and flared by coring the concavity of the first $\mathrm{I}-2 \mathrm{~mm}$ of the tip (B).

\section{Punch Optimization to Reduce Injury from Subsurface Angulation}

As a conventional FUE punch scores deep into the hair follicle, it relies on the relative straightness of the follicle to avoid transecting it. When the subsurface course of a hair follicle is significantly curled, the tip of the punch tends to transect the graft at the point of the curl bend. The allpurpose punch overcomes this issue through a patented texturing $^{11,17}$ of both the inner and outer surfaces of the first few millimeters of the cutting end (Figure 6). This texturing creates a corkscrew-like effect during axial motion that pulls the grafts into the lumen of the advancing punch, away from the crosshairs of the cutting tip (Figure 7). ${ }^{11,17,18}$

\section{Punch Optimization to Reduce Crush Injury}

As a conventional FUE punch descends into the tissue containing the follicle, any buildup of tissue in the lumen can interfere with the ascent of the follicle into the punch lumen. In that event, the bulbar segment of the follicle still distal to the punch becomes vulnerable to crushing or cutting by the tip of the advancing punch (Figure 8). The pulling effect of the texturing coupled with the spaciousness of its frustoconical lumen of the all-purpose punch reduces this risk by sustaining the ascent of the follicle and minimizing luminal tissue buildup.

\section{Punch Optimization to Reduce Burying of Grafts}

The pulling effect of the texturing minimizes graft burying when the punch, rather than scoring around the graft, pushes the graft into the hypodermis. Buried grafts are a well-known FUE phenomenon, most commonly found in the use of dulled/blunt punches.

\section{Punch Optimization for Minimal-Assist- Navigation}

One of the hallmarks of the all-purpose punch is the phenomenon of minimal-assist-navigation (MAN). When the first portions of the textured surfaces engage the skin, the rotating punch pulls itself along to trace the subsurface 

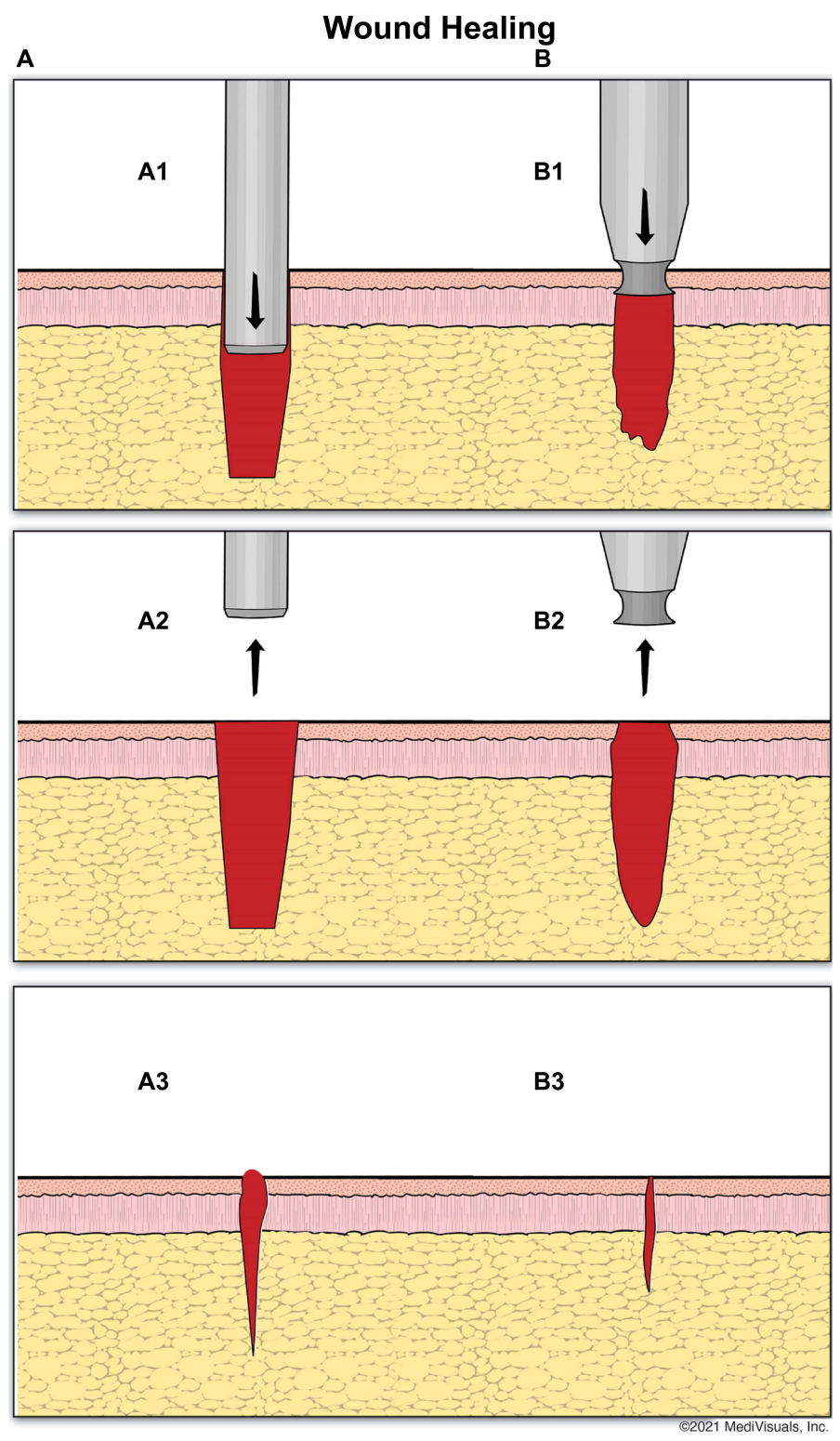

Figure 4 The wound-healing advantage of the flared all-purpose punch. (A) AI-A2: outer beveled punch cutting axis, directed downwards and inwards, cuts a cylindrical wound column with a relatively everted papillary dermal edge; A3: most of the wound closes primarily due to wound contraction. The top papillary portion remains patent, relying more on second intention healing for wound closure and resulting in a larger scar; (B) BI-B2: The flared punch cutting axis, directed outwards to bite into the tissue lateral to the punch. The first cut into the papillary dermis cuts a wound path that is relatively inverted compared to that of non-flared punches, resulting in a cylindrical wound column with a relatively inverted papillary dermal edge; B3: most of the wound closes primarily due to wound contraction, including the majority of the wound's top papillary portion, bringing the edges closer together, such that the entire top part either closes by primary intention or recruits a relatively smaller degree of second intention, healing with less scarring.

course of the follicle, with minimal or no operator guidance. This property of MAN results from a combination of the various design features described above. The MAN phenomenon may be instructive for experienced FUE providers who need to learn to release control of the navigation and allow the punch to guide itself through the subsurface depths of the follicle. The phenomenon also compensates for the changing course of hair grafts (Supplementary Video 1). The advantage of MAN becomes evident during FUE in patients of African descent and in body hair FUE, where hair curliness presents an additional challenge.

\section{Mobile Donor Area and Minimization of the Need for Tension/Tumescence}

In previous FUE devices, the operator often needed to apply tension or tumescence to align grafts better and present a more stable surface to the tip of the cutting 
A

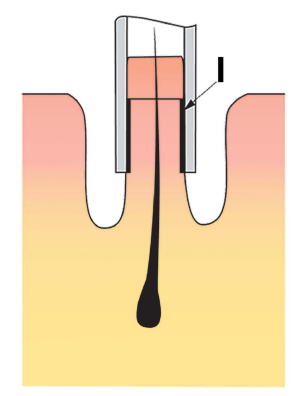

B

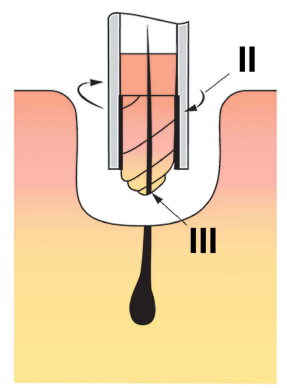

C

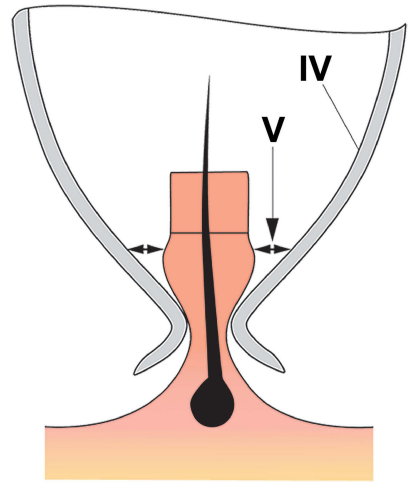

Figure 5 (A and B) Friction between the graft and punch lining - I causes the graft and punch to rotate in unison - II relative to the fixed distal portion of the graft, resulting in twisting and torsion damage - III (C) Frustoconical rooming of the punch lumen - IV minimizes friction between the inner surface of the punch and the graft - V thereby reducing the risk of torsion damage.
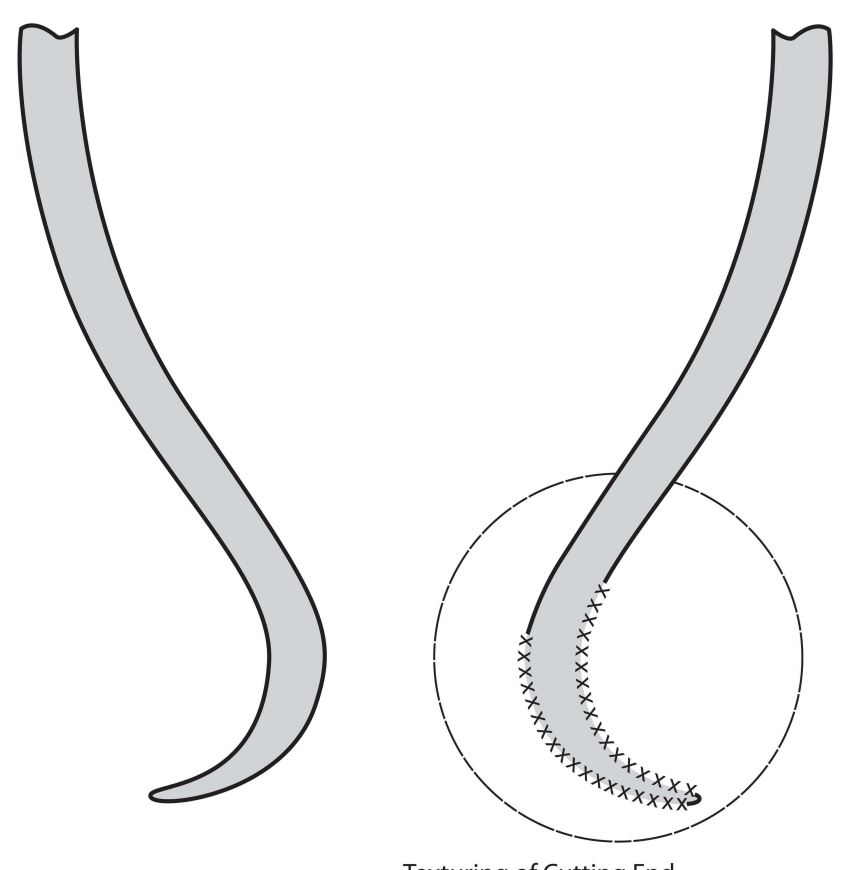

Texturing of Cutting End

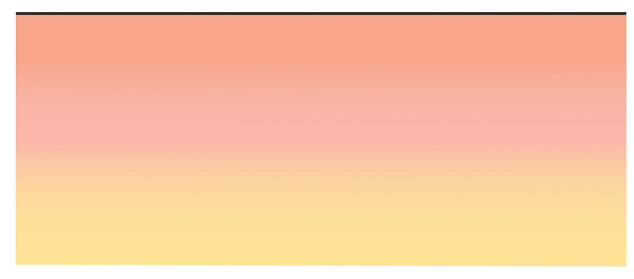

Figure 6 Patent application schematics show the texturing on the inside and outside of the punch.

punch. ${ }^{20,21}$ The texturing of the all-purpose punch minimizes this need because once the textures engage the skin, the punch navigates the subsurface course of the follicle to complete the score with minimal operator guidance. This benefit is evident in abdominal zones, where the donor area moves with each breath.

\section{Course Correction in Hair/Punch Axis Misalignment}

The advantage of MAN includes the ability to coursecorrect for a roughly 20-40 degree misalignment of the punch-hair axis along all points within the $\mathrm{X}, \mathrm{Y}$, and $\mathrm{Z}$ planes. This makes the procedure less challenging to master and less difficult ergonomically. In addition, the practitioner does not need to contort or reposition themselves to align the punch precisely to changing hair angles and directions (Supplementary Video 2).

\section{Elimination of the Need for Suction}

While vacuum suctioning also exerts a pulling effect on the grafts, its pulling force is not refined enough to respond to the delicate amount of pulling needed for consistent MAN, provided by the all-purpose punch's textured design. Also, vacuum suction does not increase or decrease with changing skin characteristics. In contrast, under the all-purpose punch driver, the texturing of the punch allows for a more intuitive MAN, with the main influencing factors being the speed and torque of the driver, which, in turn, are influenced by the firmness and thickness of the skin. In addition, eliminating suction minimizes the additional sterilization requirements from the suctioning of bodily tissues and fluids into the device.

\section{Responsiveness to Changing Skin Thickness and Firmness}

The all-purpose punch contributes to the device's responsiveness to changing skin thickness and firmness in two ways. First, the texturing imparts a discernible resistance to the 


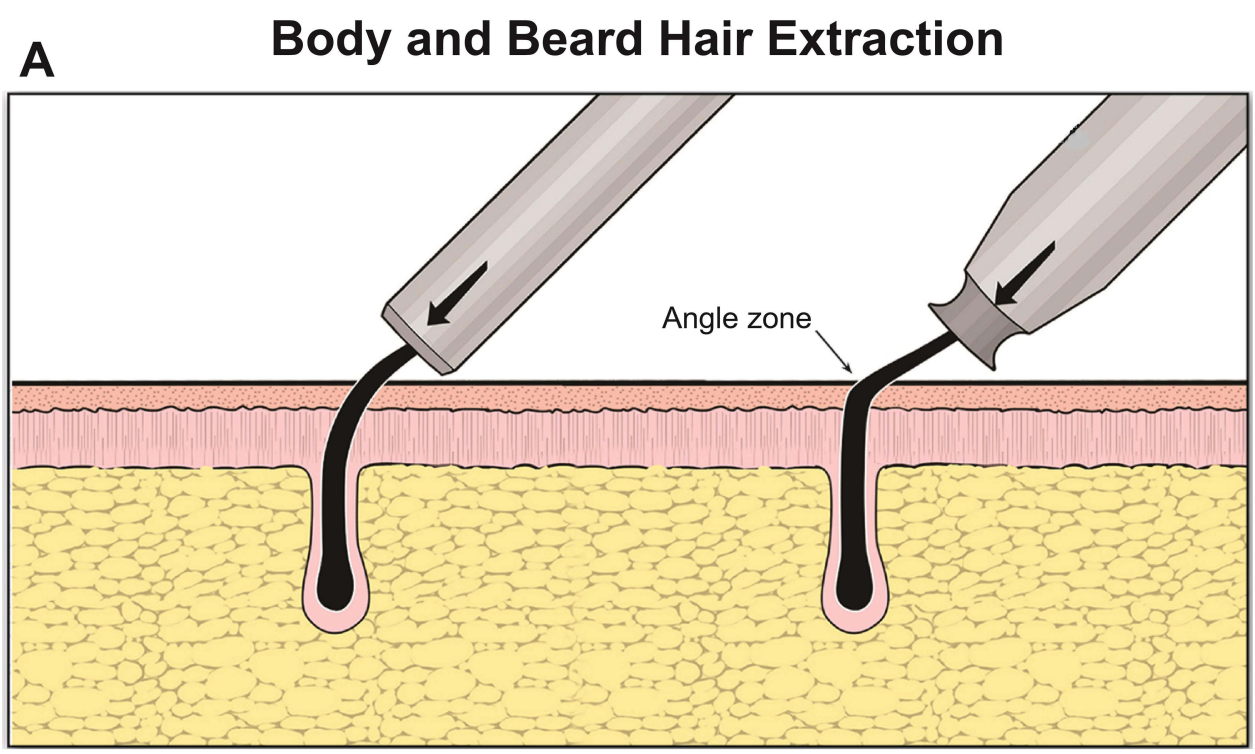

B

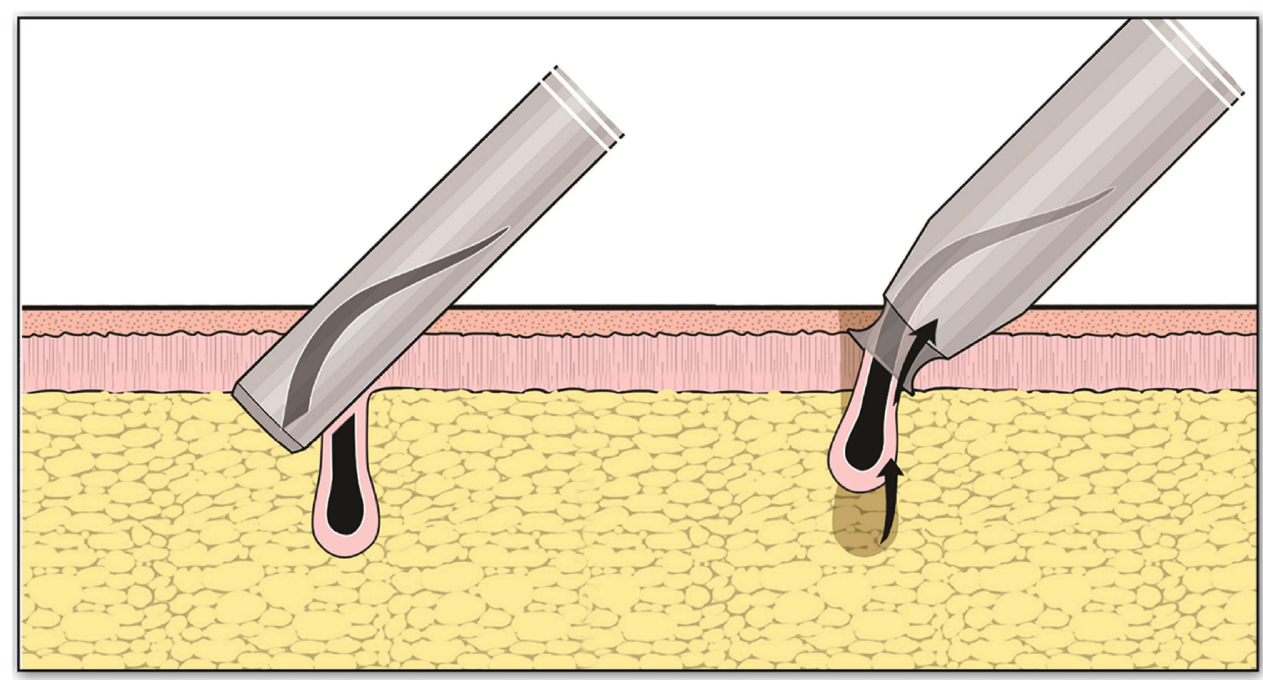

(c)2021 MediVisuals, Inc.

Figure 7 The angular point of the graft in the crosshairs of the cutting edge of advancing punches. (A) A conventional punch transects the angulated hair follicle at its maximum inflection point; (B) The textured all-purpose punch pulls the follicle, keeping the angulated portion inside the punch lumen before contacting the cutting tip of the punch.

corkscrew dynamics that provide the punch with a natural tendency to slow down or stop, depending on the skin's firmness, as each of the texturing grains interacts with the tissue. ${ }^{11,17}$ Second, the frustoconical shape presents a smooth surface to the surrounding tissue that meets a resistance that steadily increases as the punch progresses into the skin (Figure 9A). The increasing resistance is affected by the depth and firmness of the skin. With increasing depth and skin firmness, the punch's rotation intuitively decreases (Supplementary Video 3). Such a decrease implies less energy to transect the graft but sufficient energy to progress the score and free the graft. The frustoconical dimension was further optimized to facilitate the blunt separation of the hair follicle from its anchoring apparatus (Figure 9B), ${ }^{20}$ such that the graft can exit with minimal effort (Supplementary Video 3).

\section{Skin-Responsive Punch Driver}

The design of the all-purpose punch driver overcomes some of the FUE challenges mentioned above by responding to the skin-sensitive feedback it provides. The device design achieved this by considering the significant importance of torque. The wide range of torque calibrations interacts with slight variations in skin resistance through feedback received from the all-purpose punch, which has 


\section{A}

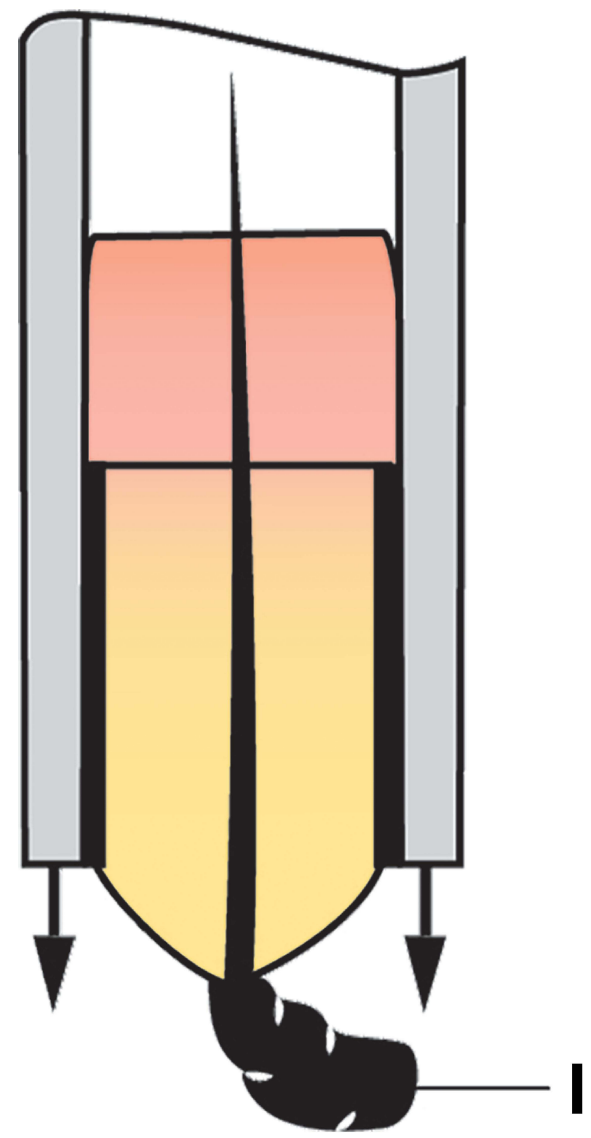

B

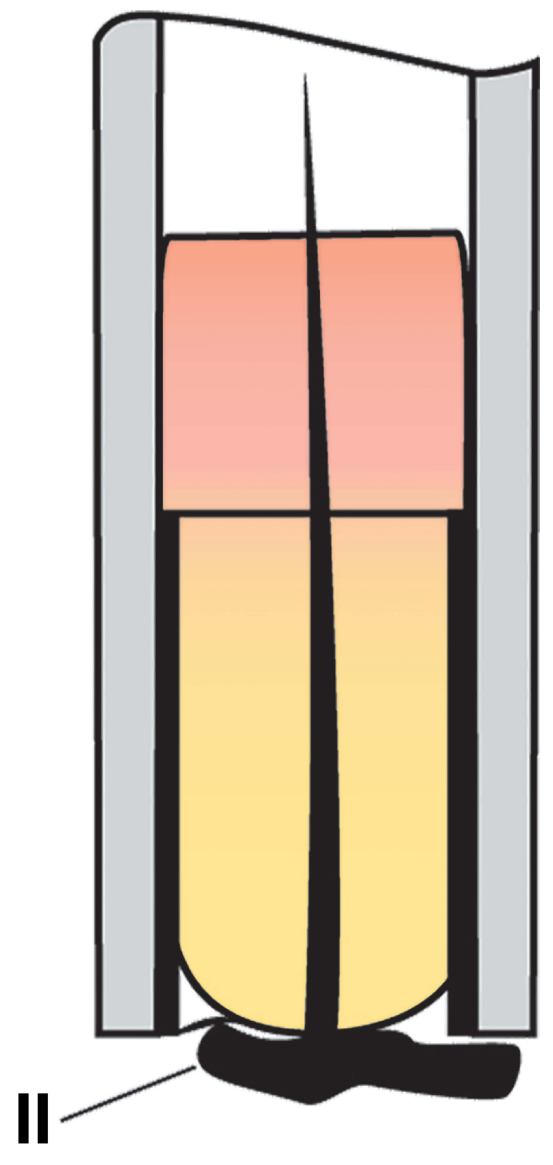

Figure 8 Patent application schematics demonstrating the crush injury phenomenon. (A) Friction impedes the follicle's upward ascent, leading to the bulbar portion of the follicle $-I$ to be crushed as the punch descends on it - II (B) Crush injury risk is minimized by the all-purpose punch's texturing, which actively pulls the graft into the punch lumen. Impaction is further minimized by the punch's spacious frustoconical design.

a frustoconical, textured end designed to enhance such feedback. An earlier model of the all-purpose FUE device - Dr. UGraft Revolution (Dr U Devices Inc, Manhattan Beach, Ca) only executed a single-mode movement per score (revolutions or oscillation). A newer model Dr. UGraft Zeus (Figure 10A), enabled compound movements. The general principle of FUE dynamics holds that, while revolution allows a faster procedure, the graft attrition rates are higher than those of oscillation. Although oscillation is slower, it registers less graft damage because it minimizes torsion injuries. ${ }^{21}$ A compound FUE movement capable of discharging more than one movement type per score phase ${ }^{22,23}$ carries the advantage of speed by executing a revolution movement mode at graft points of lower risk of transection and oscillation where transection is more likely.

Overall, the all-purpose FUE device incorporates torque such that, at the appropriate torque and speed settings, the punch stops after separating the graft from its lateral attachments (Supplementary Video 3). Thus, instead of relying on the practitioner's experience of knowing when to pull out the punch or using mechanical guards ${ }^{5,9}$ or an automatic timeout mechanism of depth control, ${ }^{24}$ the allpurpose FUE device intuitively takes its cue mainly from the resistance of the tissue to determine the appropriate depth. $^{17}$

In contrast, in previous devices in which the punch and driver-torque were not coordinated enough, the punch would brutally enter the skin, regardless of the resistance offered by the tissue, requiring operator intervention - for example, when the all-purpose punch driver is used with a conventional punch (ie, not the all-purpose punch), the feedback mechanism and the associated benefits are lost. Furthermore, the design of the new driver system incorporates an optional fluid flush system. This fluid system also delivers a steady drip of fluid to the tip and lumen of the 
A

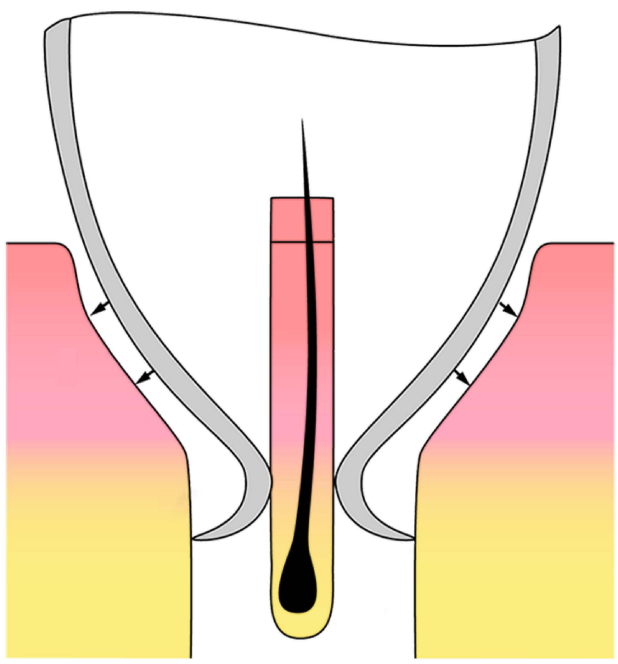

B

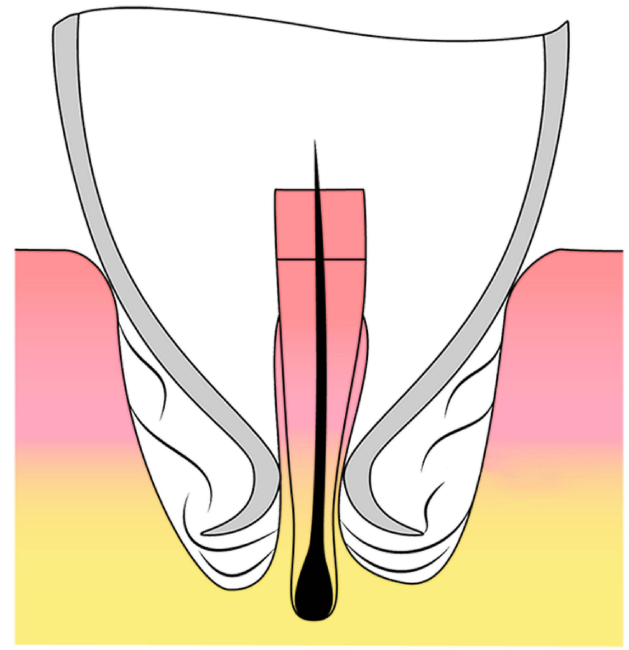

Figure 9 The frustoconical punch shape $(\mathbf{A})$ increases the resistance with deeper punch penetration. (A) Resistance increases with the firmness and thickness of the tissue and (B) causes blunt separation of the lateral anchoring elements.

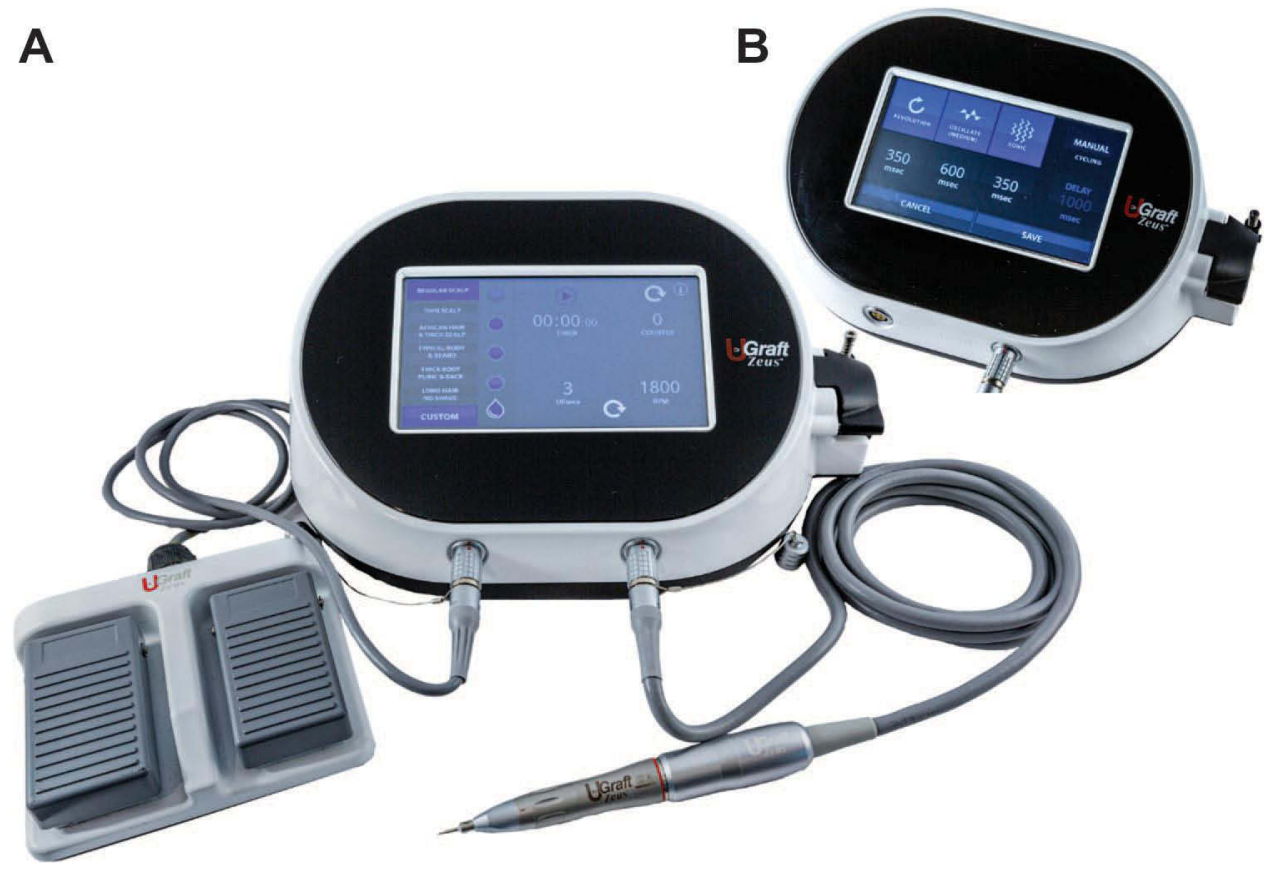

Figure 10 The all-purpose FUE device: (A) Main Panel: The system, consisting of the console, hand piece, foot pedal, and optional fluid integration. The dashboard shows six presets, custom mode, torque control, speed, timers, and reset features; (B) inset: The dashboard displays three movement modes, adjustable movement duration, score intervals, and automatic/manual modes.

punch, thereby minimizing the friction between the follicle and the punch's inner lining, further reducing torsion and graft attrition. ${ }^{25}$

\section{Method of Use}

In previous FUE devices, the operator must align the punch's long axis to precisely align with the long axis of the hair exit angles on the skin or risk graft loss. ${ }^{4,5,9}$ In contrast, the novel device corrects for roughly 20-40 degrees of misalignment through its MAN feature. Thus, the practitioner does not need to be exact in punch-hairaxis alignments. At optimal settings, the system would typically auto-pilot to complete the score under its weight and direction. The practitioner simply props it up loosely 
without trying to control the path of the device. With experience, the operator may learn to share control and find an optimum rhythm (Supplementary Videos 1 and $\underline{3}$ ).

The method of using the intuitive system is described below.

\section{Scalp and Beard}

For scalp and beard hair, the hair exit angles on the skin are steeper. In these cases, the punch can be held in the general alignment of the hair, with a wide range of angulation, because it corrects for roughly 20-40 degrees of misalignment of the punch relative to the hair axis, at any point between the X, Y, and $\mathrm{Z}$ axes of the hair angle. Generally, holding the punch at nearly 90 degrees to the skin typically works (Supplementary Videos 3, $\underline{4}$ and $\underline{5}$ ).

\section{Body Hair}

Body hair exits the skin at more acute angles. Here, the system corrects 20-30 degrees of misalignment anywhere between the $\mathrm{X}, \mathrm{Y}$, and $\mathrm{Z}$ axes of the hair angle. Thus, generally, holding the punch at nearly 60 degrees to the skin typically works (Supplementary Video 1).

\section{Speed}

The advanced FUE device comes with a manual mode option, in which a foot pedal press initiates each score and an automatic choice. In the automatic mode, the operator chooses to have the unit discharge a score at chosen intervals ranging from 250 to $4000 \mathrm{~ms}$, with intervals of $250-\mathrm{ms}$ unit increments. Thus, the operator may establish a rhythm that scores a graft between every $0.25-4 \mathrm{~s}$ (Figure 10B).This provides a wide range of inter-follicular scoring speeds of between 500 to over 2500 grafts per hour.

\section{Results}

Three case examples illustrate how the new FUE equipment and techniques can assist in solving the diversity of challenging FUE donor harvesting scenarios.

The versatility of the all-purpose FUE device to tackle typical scalp, beard, and body FUE was demonstrated in a 63-year-old Caucasian male (Case 1) whose Norwood (NW) 7 hair loss was compounded by retrograde alopecia. The patient, who possessed a scalp of typical thickness, requested a global restoration of his NW 7 bald areas (Figure 11). Using the all-purpose FUE device, 9585 hair follicles were successfully harvested from the head, beard, chest, stomach, forearms, and pubic areas to achieve his goals (Figure 12). The average graft attrition rate was $4 \%$. Next, the all-purpose device's capability in harvesting follicles in the setting of a thick, firm scalp and tightly curled hair shafts with chaotic hair-exit-angles was illustrated in a 26-year-old African (Case 2) who presented with a Norwood 5 area of baldness. Using the new device, FUE transplantation was successfully performed to attain good coverage (Figure 13). The average graft attrition rate was $7.5 \%$. Graft attrition was lowest in the mid-occipital areas (5\%) and highest in the parietal areas $(10 \%)$. Finally, the new device exhibited success in long hair FUE in a 33-year-old Caucasian male (Case 3) with NW 2 hairline recession who wanted to avoid

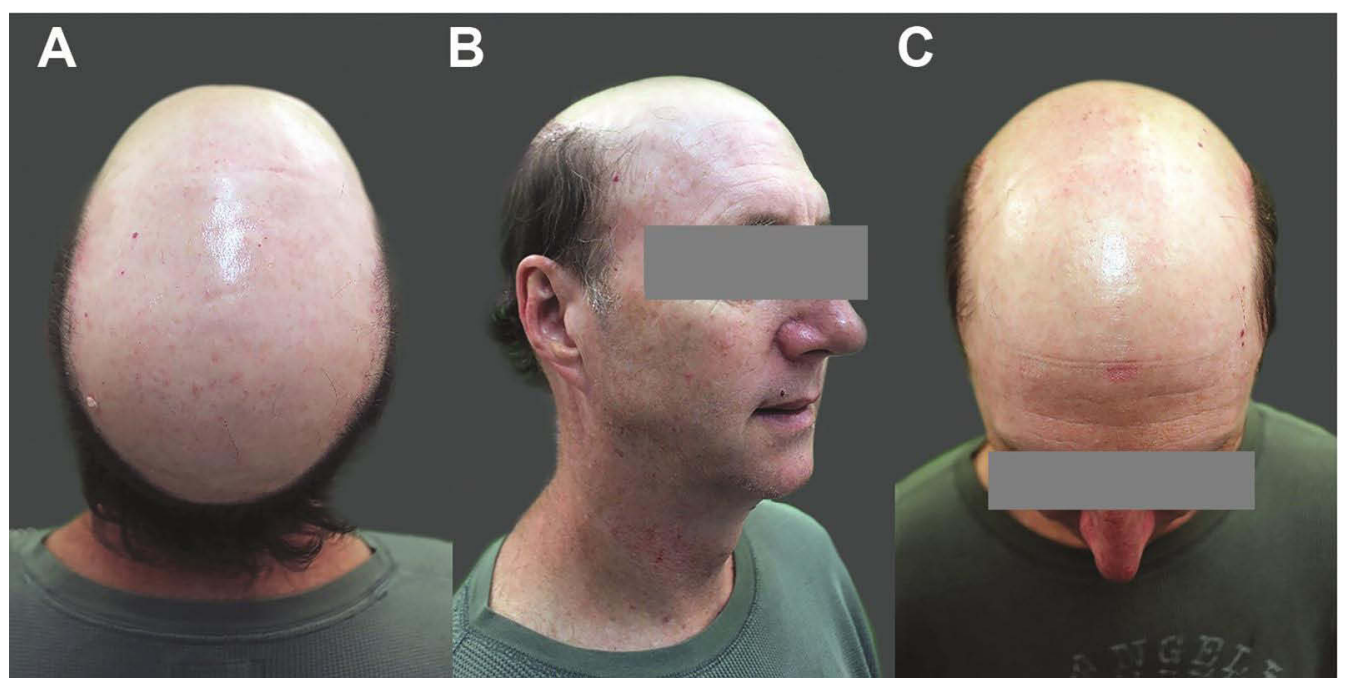

Figure I I Case I, a 63-year-old Caucasian male with Norwood (NW) 7 hair loss compounded by retrograde alopecia. (A) Bird's eye view from the back; (B) right oblique view; and (C) bird's eye view from the front. 


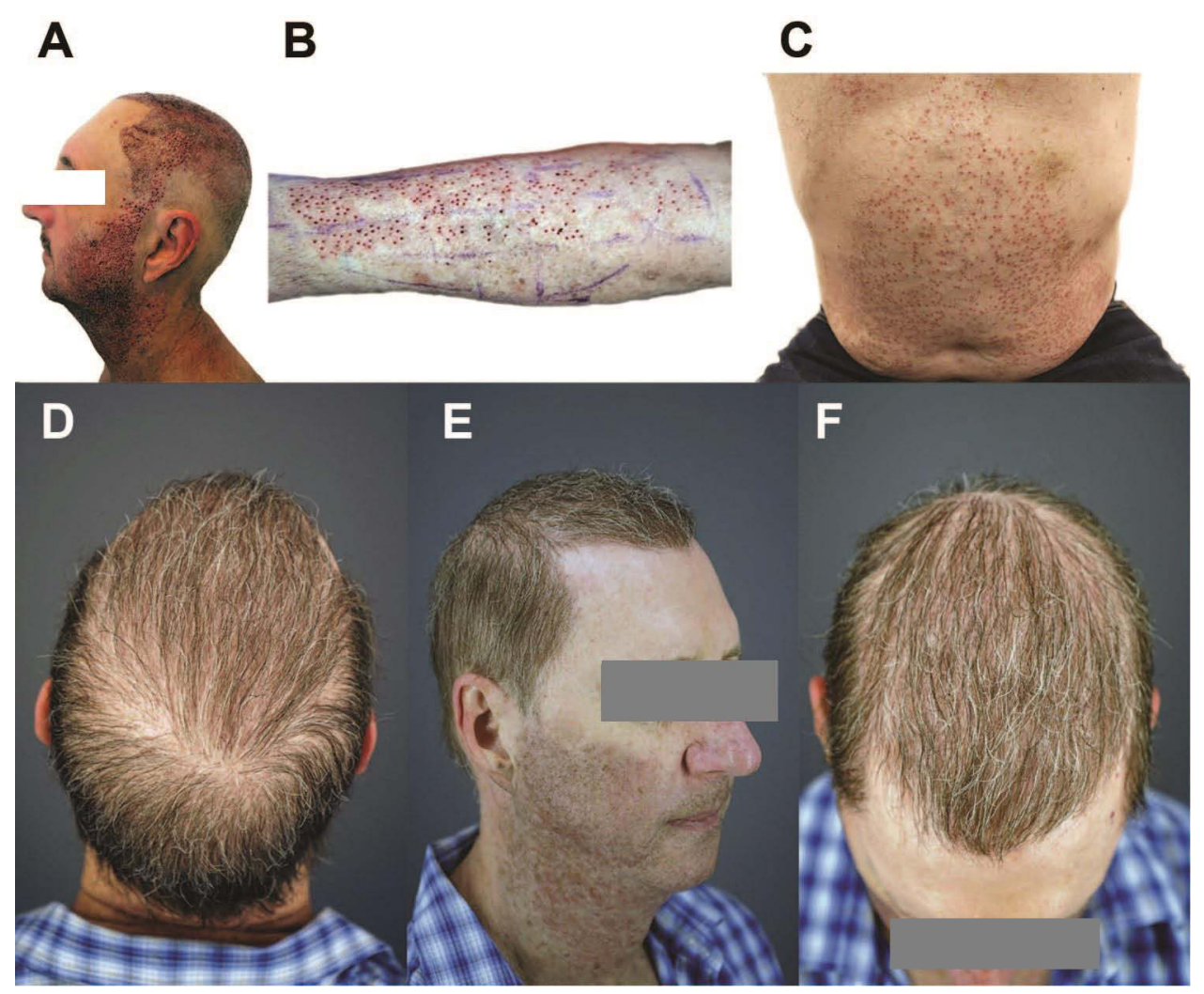

Figure I 2 Case I: Using the all-purpose FUE device, the Average Head Skin Thickness/Firmness, Body Hair Areas, and Beard Area hair presets were used for universal FUE. Post-operative photos of the head and beard: (A) forearm, (B) chest, and abdomen (C). Using hairs harvested from the head, beard, chest, stomach area, forearms, and pubic areas, global restoration was achieved. Results after one year: (D) Bird's eye-view from the posterior; (E) right oblique view; and (F) bird's eye-view from anterior.

shaving his head and detectable post-surgical wounds and scabbing. The all-purpose FUE device was used to extract 3289 grafts from his scalp with $\sim 90 \%$ long hair retrieval. These were used to graft his frontal area (Figures 14 and 15) successfully. The average graft attrition rate was $4 \%$. Graft attrition rates were lowest in the mid-occipital areas (3\%) and higher in the parietal zones $(5 \%)$.

Graft attrition rates were determined by average rates between zones of lowest graft attrition per 100 punch scores and zones of highest attrition per 100 score of any given body area.

All cases were performed using the all-purpose punch driver in conjunction with the same all-purpose punch without deviating from the standard methods described in the "method of use" section of this manuscript. There was no need to switch devices, punch types, or design for any of the diverse FUE scenarios. No special skills outside the standard approaches described in this article were used. Supplementary Videos 1- -5 demonstrate the techniques used.

\section{Discussion}

Most FUE devices are designed to score around a straight hair graft axis. ${ }^{9}$ Consequently, these devices are challenged by hair grafts with an angular or tortuous subsurface course. ${ }^{4}$ We report an all-purpose FUE device that corrects for both the subsurface course taken by the hair follicle and changing skin characteristics. The premise for this approach is the observation that the primary factor varying across donor areas that affect a device's graft attrition rates is the viscoelastic properties of the skin. These properties correlate to the firmness and thickness of the skin. ${ }^{5}$ Changing skin thickness and firmness accounts for the following everyday observations by FUE practitioners:

1. Intra-patient variation in the graft attrition rate in the same individual during graft extraction from the mid-posterior occipital zone compared to the midparietal areas of the same patient, even though hair caliber, angulation, and shape remain unchanged and the operator is using the same device. ${ }^{6}$ 

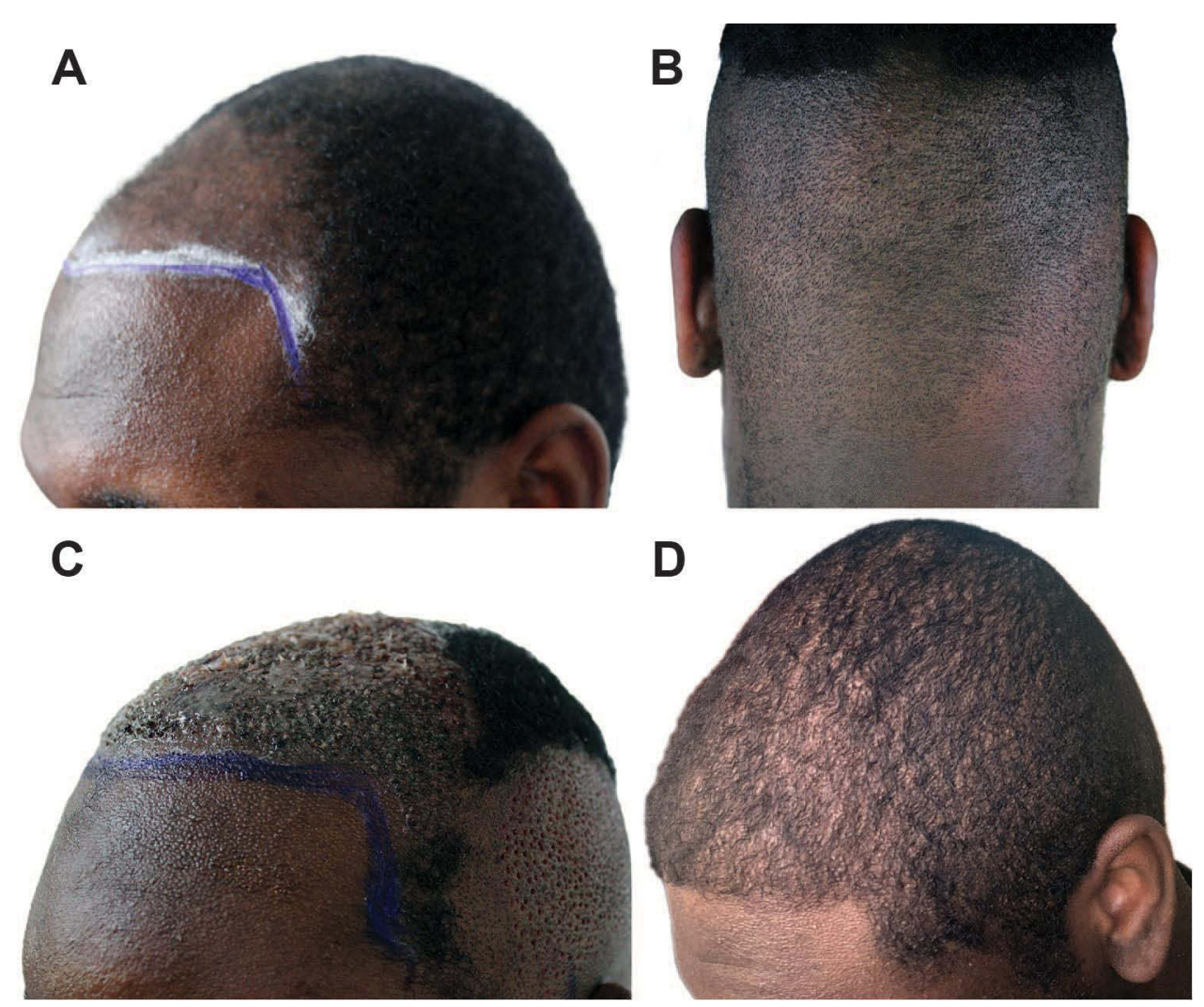

Figure 13 Case 2, a 26-year-old African American male undergoing FUE transplantation with the all-purpose FUE device set at moderate torque, oscillation mode, and an 18-G punch. (A) Frontal area before transplantation; (B) donor area showing chaotic hair exit angles; (C) the frontal area soon after grafting and the head donor area soon after extractions; and (D) results at II months after surgery.

2. In patients of African descent with very curly hair, conventional FUE devices do very well in those with softer, thinner skin. In contrast, graft attrition rates are very high in those with relatively less curled hair but thicker, firmer skin.

3. Certain patients, mainly of North African and Middle Eastern descent, whose hair is Caucasoid, or loosely curled, have higher than typical graft attrition rates because of skin characteristics.

Thus, there is a need for a device versatile enough to accommodate most or all FUE scenarios and comprehensively correct for both subsurface hair angulations and the changing firmness and thickness of the skin containing the hair shaft.

\section{All-Purpose Skin-Responsive FUE Device}

The dashboard of the all-purpose FUE device features the following preset options for the operator (Figure 10B):

(I) Average thickness/firmness scalp

(II) Thin/soft scalp

(III) Thick/hard scalp
(IV) Beard or facial area

(V) Body area

(VI) Long hair

(VII) Custom

Thus, the preset keys for head hair FUE (I-III) are configured regardless of the race or hair phenotype and considering only the skin characteristics.

\section{Scalps with Average Skin Thickness/ Firmness}

Scalps with average skin thickness and firmness typically fare very well with all types of FUE devices. Most Caucasian scalps, as exemplified by our case \#1, fall into this category (Figures 11,13A, and Supplementary Video 3). Even patients of African or mixed descent who may have very tightly curled hair but relatively thinner/softer scalp skin would fall into this category, and they would do well with conventional FUE. The optimal settings of the new device are mid-level torque in continuous rotation (older model) alone or a compound movement of initial revolution followed by oscillation (New FUE device) 


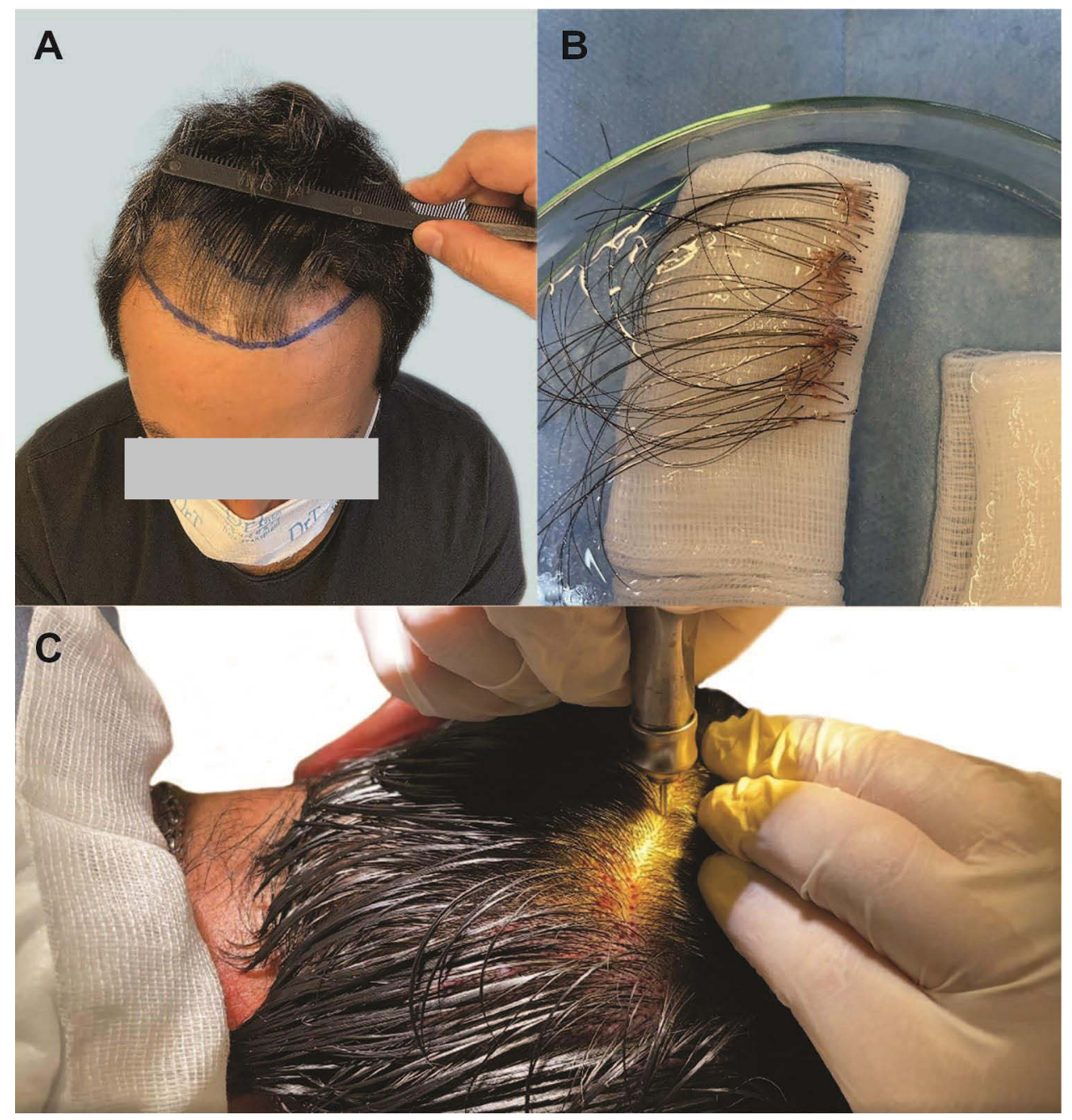

Figure 14 Case 3, a 33-year-old Caucasian male who requested non-shaven FUE with long hair to prevent obvious post-surgical scabbing and wanted to preview what the recipient area might look like with the final growth. The all-purpose FUE device extracted 3289 grafts in a 2.5 -h period, with $90 \%$ long hair retrieval and a 3-4\% graft attrition rate. (A) The frontal area before grafting; (B) long-hair grafts; and (C) hand piece alignment at 90 degrees obviates the need to guess the hair exit angle.

(Figure 10A). Ideal settings are low torque (setting -2 ), with a revolution phase speed of 2400-2600 rpm (Figure 10B). The recommended all-purpose punch sizes are 20-19G. In the newer model of the all-purpose device, the operator begins FUE in donor scalps of average thickness and firmness by touching the preset option on the dashboard for that skin type.

\section{Thin/Soft Scalp}

Thin/soft scalp skin is fragile and liable to damage. ${ }^{12}$ With conventional FUE devices operating in continuous rotation and at high speed, these patients record high hair graft attrition rates, with a significant occurrence of decapping (when the top portion of the graft comprising the epidermis and dermis is decapitated, leaving behind a firmly rooted follicle that is not separated from its attachments and, as such, is irretrievable). The all-purpose FUE device optimally overcomes this by its skin-responsive, low-torsion-risk punch working only in oscillation mode and at shallow torque ranges. Ideal settings are a very low torque of -1 and a low speed of 1400-1600 rpm (Figure 10B). Adding fluid to the tip further reduces friction torsion. The recommended all-purpose punch sizes are 20-19G. In the newer model of the all-purpose device, the operator begins FUE in thin/soft donor scalp scenarios by touching the preset option on the dashboard for that skin type.

\section{Thick/Firm Scalp Skin}

Patients with significantly thicker/firmer than average skin are considered challenging or poor candidates for FUE by conventional devices. Often, very large traditional punches are resorted to, while some practitioners develop specially 

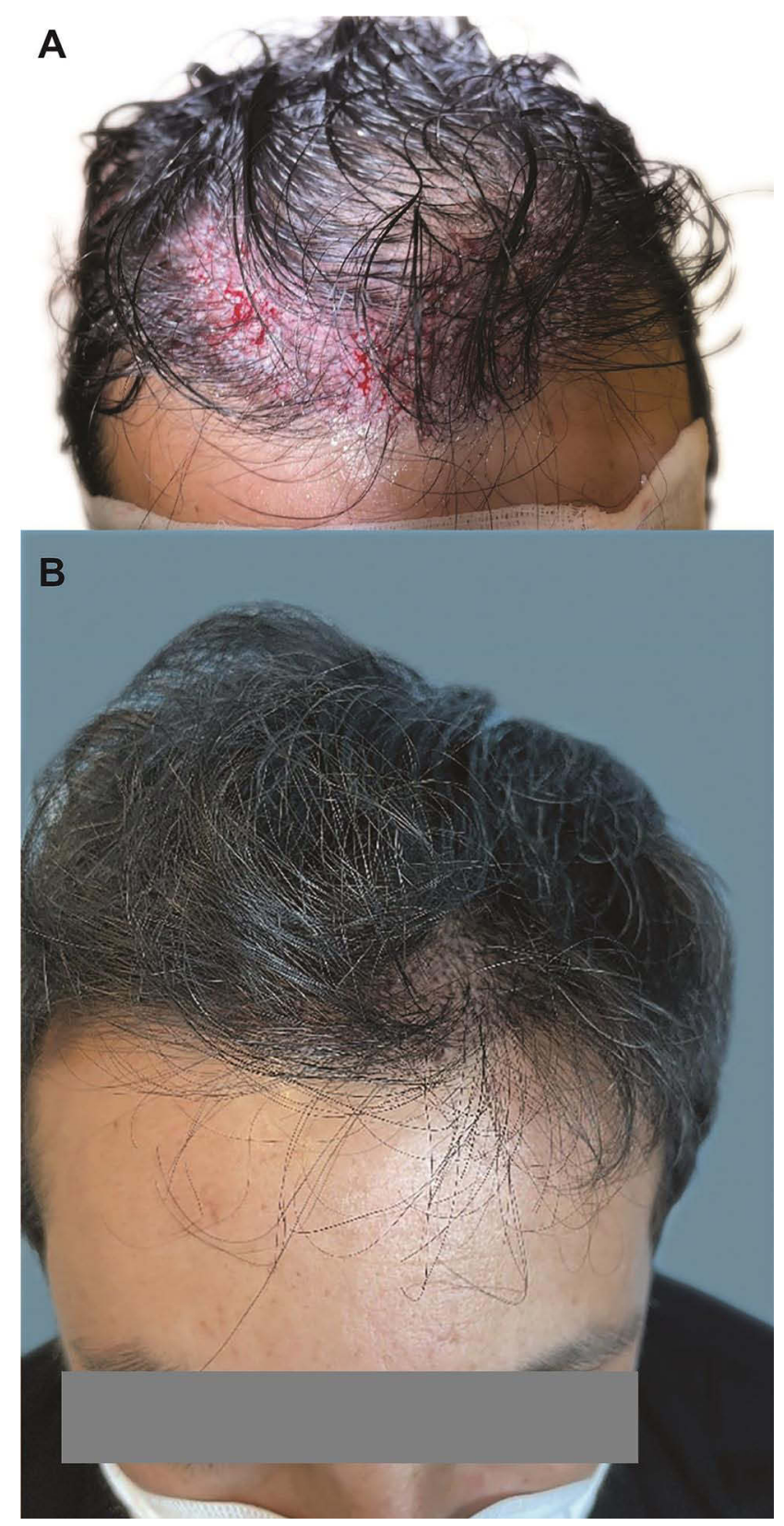

Figure 15 Case 3: (A) Frontal scalp soon after grafting; and (B) frontal area with minor signs of surgery at $48 \mathrm{~h}$ after long-hair implantation.

acquired skills to overcome the challenge. ${ }^{2,10}$ As shown in case $\# 2$, most of the patients in this category have curledto-kinky hair and are of African descent (Figure 13); some have relatively loose, wavy, or even straight-looking grafts. Some North African and Middle Eastern patients with hair that is not Afro-textured could challenge conventional FUE due to this skin phenotype. In the newer model of the all-purpose device, the operator begins FUE in thick and firm donor scalp scenarios by selecting the preset option on the dashboard for that skin type.
With its intuitive FUE abilities, the all-purpose FUE system is consistently successful in these cases, with punch speed and torque kept below typical conventional FUE parameters. It consistently extracts hair follicles with much lower graft attrition rates than traditional FUE systems without changing the method of use or requiring extraordinary operator skill (Supplementary Video 5). The punch size should be such that it can engulf follicles at their exit point. Generally, mid-level torque in the oscillation movement mode of the FUE system is used. In most individuals, the punch must be $18-19 \mathrm{G}$ because of the typically wider hair-shaft-exit-point distances between the individual hair units in a follicular unit bundle and the relatively large hair shaft calibers that usually characterize this demographic group. FUE graft attrition rates are typically kept below $10 \%$, even in the most challenging cases. Our second author, who practices in Africa, reports registering attrition rates of $>50-60 \%$ with prior use of conventional FUE, while the rates reported with the new device are consistently below $10 \%$, and even below $5 \%$. Before, the same author would perform a 25-50 graft test FUE to establish viability before booking patients of African descent for an actual procedure. After using the all-purpose device, the author no longer requires a pretest, given the uniform consistency in the novel device's performance.

\section{Beard or Facial Area Hair}

The beard area and other facial skin are thin, but relatively firm, compared to scalp skin. The hair shafts are thick, wiry, and more resilient to the rigors of FUE. Furthermore, although more angulated than scalp hair, the hairs are less angulated than body hair. Finally, the attachment zone to the surrounding skin is relatively superficial, being unattached for most of its depth. ${ }^{4}$ Consequently, beard hair is somewhat easy to extract by FUE using conventional methods. However, traditional methods typically register higher graft attrition rates in the lower neck and the periauricular zones where the skin becomes thicker or the hair flatter on the skin with more severe angulation and a broad zone of skin attachment. In these problematic areas, the all-purpose FUE device has advantages for beard hair FUE, allowing the efficient use of facial hair as donor areas (Figure 12A). This capability extends to beard extraction in patients with African-type hair and skin phenotypes where previous FUE systems typically fail. When using the new system, the preferred movement mode is a low torque of -2 and a clockwise revolution speed of 
2500 , although this may be preceded by a brief spurt of oscillation for the first skin cut. In the newer model of the all-purpose device, the operator begins FUE in the beard area by selecting the preset option on the dashboard for the beard.

\section{Body Area FUE}

As one progresses from the neck, body hairs invariably become angulated in relative and severe contrast to the same individual's scalp and even beard hair. Furthermore, the angulation level differs from one body area to another, generally increasing as one progresses centrifugally outwards from the neck as a focal point. Some body locations present unique challenges compared to other body areas. For instance, back skin is much thicker than the chest, whereas pubic hair exhibits more acute angulation and an extensive zone of skin hair attachment compared to the chest. The abdomen presents the challenge of abdominal movement with breathing.

The new device overcomes these challenges because of the features mentioned above [Figure 12B and C, Supplementary Video 1]. For instance, in the stomach area, because of its MAN ability, once the first cut is initiated, the punch completes its score to successfully retrieve intact grafts undeterred by intervening movements of the abdomen [Figure 12C]. The sum effect of a versatile all-body and beard-harvesting capability is the ability to credibly restore head donor-challenged individuals, as shown in case \#1 (Figures 11 and 12). The ideal setting is a low-level torque and continuous clockwise rotation, which may have a brief oscillation at the end of the score. A torque of -2 and a speed of $2500 \mathrm{rpm}$ are optimal. In the new model of the all-purpose device, the operator begins body area FUE by selecting the preset tab on the dashboard for body hair.

\section{Non-Shaven FUE and Long Hair FUE}

Non-shaven FUE is an option preferred by those who wish to avoid the downtime that head-shaving entails. Most conventional FUE punches enable FUE without shaving when used in oscillation mode. However, the extracted grafts are short-haired, as the punches cut off the hair shafts within $0.5-1.5 \mathrm{~mm}$ of the skin exit point. ${ }^{25}$ A subset of non-shaven FUE patients prefer long-haired grafts. The objectivity of this procedure is debatable, however, since implanted hair shafts are typically not retained past two months, as they are shed from the telogen effluvium to which transplanted grafts are typically subject. ${ }^{26}$

Nevertheless, many special punches have been devised to perform non-shaven FUE with the primary objective of yielding mostly long-haired grafts. ${ }^{7,27,28}$ These special punches commonly feature a groove/slit on the cutting end of the punch wall. The slit design ranges between a partial groove that engraves only the bottom tip of the punch wall, ${ }^{7}$ and another where the groove extends fullthickness a few millimeters up the length of the distal end of the punch. ${ }^{26,27}$ These grooves/slits make room for the hair shaft to enter the lumen without the punch sliding over it and losing its balance, forming a safer passage for the hair shaft between the punch cutting tip and the skin when the punch cups the graft during scoring. However, as demonstrated in case \#3, the all-purpose FUE device performs long-haired non-shaven FUE using the same allpurpose punch, which does not feature any groove/slit in its design (Figures 1, 14, 15, and Supplementary Video 3). The ability of the all-purpose punch to perform longhaired FUE in its novel way is due to the following:

1. The flared tip of the all-purpose punch helps engulf/ cup the skin exit-point of the hair follicle, together with the long hair shaft that curls up inside the punch. The funnel-shaped tip of the punch allows easier cupping without losing its balance. Furthermore, the punch is not as sharp as conventional punches; hence, the edges glide over rather than cutting the hair shaft.

2. The internal texturing drives the long hair shaft into the punch's lumen, preventing it from building up, thus minimizing the risk of being cut.

3. Generally, in conventional shaved head FUE, the operator guesses the subsurface hair path based on the external skin-exit-angle of the first $1-2 \mathrm{~mm} .{ }^{26}$ This ability is lost with long hair, making long hair FUE problematic and subject to graft attrition. Since the allpurpose punch does not require this alignment, and the standard method of use in the scalp entails holding the punch at roughly 90 degrees to the skin (Figure 14C, Supplementary Video 4), this issue is mitigated.

4. The capacious lumen of the punch presents enough room to accommodate the graft and a long hair shaft with minimal friction. Thus, the risk of transection of either the graft or its accompanying long hair shaft is reduced (Figure 16).

5. The flared, outward-facing cutting tip design is less likely to cut the long hair shaft underneath it than straight-edged punches, whose tips point downwards directly in the part of the hair shaft. With the allpurpose punch, the bulk of the hair shaft abuts the 
blunt surface immediately inside the punch's cutting tip (Figure 16). Furthermore, the texturing pulls the hair shaft loop into the lumen instead of arresting and cutting it.

The optimal setting for non-shaven long hair FUE using the all-purpose device is a low-torque, shortamplitude oscillation mode in the earlier model, or in the case of the newer model of the device, an initial lowtorque and low-amplitude oscillation mode in the first movement phase, followed by a larger amplitude oscillation phase. In both versions, the initial low-amplitude oscillation mode helps glide the punch over the hair shaft instead of cutting it. Increasing the amplitude in the later model once the punch crosses the dense tighter quarters of the dermal tissue into the looser hypodermis, enhances the process because the loose tissue grants the hair shaft the latitude to move away from the advancing cutting edge of the punch (Figure 16). According to the third author, who performs a lot of long hair FUE, prior attempts to perform long hair FUE using conventional FUE devices and punches in the same manner were unsuccessful. In the new model of the all-purpose device, the operator begins non-shaven long hair FUE by selecting the preset tab on the dashboard for long hair.

\section{All-Purpose FUE Device Custom Settings}

The custom tab on the dashboard of the new device enables the user to input a setting of their choice (Figure 10), including speed, torque, and a selection of three movement modes. The operator may also choose the duration of each movement mode and whether each score is automatically or manually (foot-pedal-activated) retrieved. The automatic mode presents a choice of $0-4 \mathrm{~s}$ intervals, at increments of 0.25 . Furthermore, in any chosen preset, the operator might need to tweak any of the parameters mentioned above to suit a particular skin phenotype.

\section{Conclusion}

Conventional FUE devices are limited in their scope for the wide range of patient needs for hair transplantation. A significant challenge is a lack of a device that can optimize the different requirements that allow variables, such as hair curliness, race, skin characteristics, body/head hair location, shaven, non-shaven, and long hair FUE, affecting the quality of the FUE to be addressed. We report an all-purpose FUE device and methodology that overcomes these challenges to allow the use of a single device to present a high level of success for all FUE scenarios. Our experience suggests that further validation is warranted.

\section{Hair Shaft Engagement}
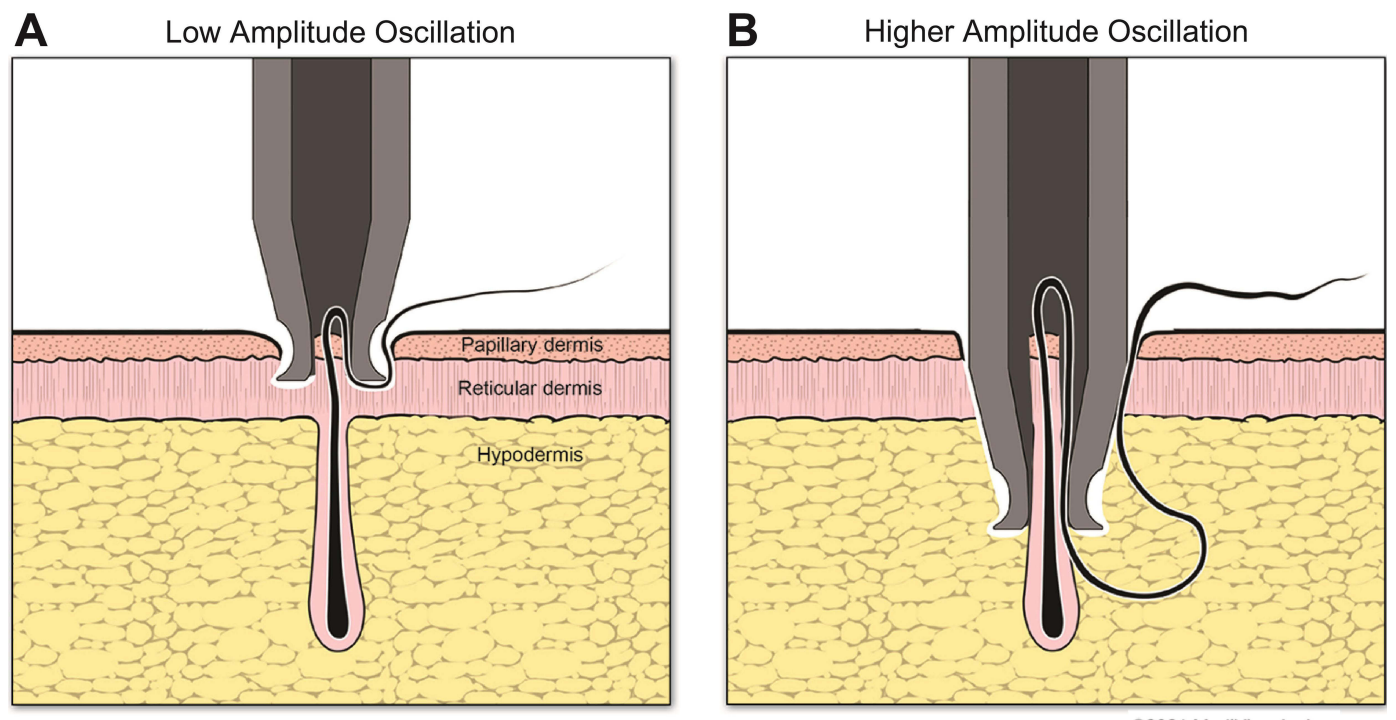

(C)2021 MediVisuals, Inc

Figure 16 The benefits of short-arc oscillations in the dermal layer followed by larger arc oscillations in the hypodermis and of the internally roomed lumen, punch tip texturing, and hybrid punch design. (A) At the dermal level, with more rigid tissue, short arc oscillations minimize the chance of cutting the hair shaft. The relative bluntness of the all-purpose punch, which glides over the hair shaft rather than cutting it, facilitates the process. The frustoconical spaciousness provides room for tissue to gather and slide through, rather than getting impacted and subject to cutting; (B) deep to the dermis, the subcutaneous layer allows room for the hair shaft to maneuver away from the punch cutting tip; the movement mode switches to wider arc oscillations for a faster, more complete separation. 


\section{Abbreviations}

FUE, Follicular unit excision; NW, Norwood; MAN, minimal-assist-navigation.

\section{Ethics and Consent}

All patients who underwent FUE provided written informed consent, including consent for publication, and all procedures were conducted in accordance with the Declaration of Helsinki (revised in 2013). Institutional Review Board approval was not required or sought as this study was not a prospective or systematic investigation of FUE treatment but described general principles for routine FUE practice.

\section{Acknowledgments}

We are particularly grateful to our patients and those who have participated in our hair transplantation work.

\section{Funding}

There is no funding to report.

\section{Disclosure}

Dr Umar owns shares, patents, and patent applications on the all-purpose FUE device issued to Dr U Devices Inc (patent nos: USPTO US8876847B2 \& USPTO US9095368B2) and pending to Dr U Devices Inc (patent no: PCT WO2019203882A1) and reports no other potential conflicts of interest for this work. The remaining authors have no conflicts of interest for this work to declare.

\section{References}

1. Rogers NE, Callender VD. Advances and challenges in hair restoration of curly Afrocentric hair. Dermatol Clin. 2014;32:163-171. doi:10.1016/j.det.2013.12.004

2. Singh MK, Avram MR. Technical considerations for follicular unit extraction in African-American hair. Dermatol Surg. 2013;39:1282-1824. doi:10.1111/dsu.12229

3. Rose PT. Hair restoration surgery: challenges and solutions. Clin Cosmet Investig Dermatol. 2015;8:361-370. doi:10.2147/CCID. S53980

4. Saxena K, Savant SS. Body to scalp: evolving trends in body hair transplantation. Indian Dermatol Online J. 2017;8:167-175. doi:10.4103/idoj.IDOJ 28316

5. Garg AK, Garg S. Donor harvesting: follicular unit excision. J Cutan Aesthet Surg. 2018;11:195-201. doi:10.4103/JCAS.JCAS_123_18

6. Mohmand MH, Ahmad M. Transection rate at different areas of scalp during follicular unit extraction/excision (FUE). J Cosmet Dermatol. 2020;19:1705-1708. doi:10.1111/jocd.13191

7. Gupta AK, Bruce A, Trivellini R, et al. Innovations hair restoration surgeons have made to adapt to the challenges of follicular unit excision. J Cosmet Dermatol. 2020;19:1883-1891. doi:10.1111/ jocd. 13506
8. Umar S. Comparative study of a novel tool for follicular unit extraction for individuals with Afro-textured hair. Plast Reconstr Surg Glob Open. 2016;4:e1069. doi:10.1097/GOX.0000000000001069

9. Gupta AK, Love RP, True RH, Harris JA. Follicular unit excision punches and devices. Dermatol Surg. 2020;46:1705-1711. doi:10.1097/DSS.0000000000002490

10. Parsa Mohebi Hair Restoration [homepage on the Internet]. Los Angeles Hair Transplant Doctor Pioneers African American FUE Hair Restoration [Press release]; September 18, 2020. Available from: https://www.prweb.com/releases/los_angeles_hair_transplant doctor pioneers african american fue hair restoration/ prweb15779280.htm. Accesse- May 18, 2021.

11. Umar S. Hair punch. US Patent No. US8876847B2; 2010. Available from: https://patents.google.com/patent/US8876847B2/en. Accessed May 18, 2021.

12. Umar S. The transplanted hairline leg room for improvement. Arch Dermatol. 2012;2:239-242. doi:10.1001/archdermatol.2011.2196

13. Umar S. Hair transplantation in patients with inadequate head donor supply using nonhead hair: report of 3 cases. Ann Plastic Surg. 2011;67:332-335. doi:10.1097/SAP.0b013e318209a61a

14. Umar S. Use of body hair and beard hair in hair restoration. Facial Plast Surg Clin North Am. 2013;21:469-477. doi:10.1016/j.fsc.2013.05.003

15. Umar S. Use of nape and peri-auricular hair by follicular unit extraction to create soft hairlines and temples: my experience with 128 patients. Aesthet Surg J. 2015;35:903-909. doi:10.1093/asj/sjv137

16. Umar S. Body hair transplant by follicular unit extraction: my experience with 122 patients. Aesthet Surg J. 2016;36:1101-1110. doi:10.1093/asj/sjw089

17. Umar S. Frustoconical hair punch. WO Patent No. 203882; 2019 Available from: https://patents.google.com/patent/ AU2018420063A1/en?q=punch\%2c+fue\&inventor=umar\%2c\&oq= umar\%2c+punch\%2c+fue. Accessed May 18, 2021.

18. Dr. U Hair and Skin Clinic. What is UGraft Advanced FUE? Results from FUE Hair Transplant [Video]. YouTube; January 5, 2014. Available from: https://www.youtube.com/watch?v=t4hsOGbAgoM. Accessed May 18, 2021.

19. Zontos G, Williams KL Jr, Nikiforidis G. Minimizing injury to the donor area in follicular unit extraction (FUE) harvesting. $J$ Cosmet Dermatol. 2017;16:61-69. doi:10.1111/jocd.12267

20. Avram MR, Watkins SA. Robotic follicular unit extraction in hair transplantation. Dermatol Surg. 2014;40:1319-1327. doi:10.1097/ DSS.0000000000000191

21. Saxena K. Safe and easy hair transplantation utilizing KD spreader. Plast Aesthet Res. 2018;5:5. doi:10.20517/2347-9264.2017.67

22. Cole J, Gutema T, Paulk H. Follicular dissection device and method. US Patent No. 9421030; 2009. Available from: https://patents.google.com/ patent/US9421030B2/en?oq=US9421030B2. Accessed May 18, 2021.

23. Cole JP. Application and tools for FUE in Asians. ISHRS Regional Workshop, Thailand; June 25-27, 2010.

24. Schambach M. Why I switched to a multiphasic FUE device. ISHRS Forum; November 28, 2018. Available from: https://www.ishrshtforum.org/content/28/6/224. Accessed may 18, 2021.

25. Umar S, Evans R. Follicular unit extraction device. US Patent No. 9095368; 2012. Available from: https://patents.google.com/ patent/US9095368. Accessed May 18, 2021.

26. Park JH, You SH, Kim NR. Nonshaven follicular unit extraction: personal experience. Ann Plast Surg. 2019;82:262-268. doi:10.1097/ SAP.0000000000001679

27. Boaventura O. Long hair FUE and the donor area preview. Hair Transplant Forum. 2016;26:200-202. doi:10.33589/26.5.0200

28. Erdogan K. Apparatus with needle for the extraction of hair follicles in long form. US Patent No. 0282260; 2019. Available from: https:// www.freepatentsonline.com/20190282260.pdf. Accessed May 18, 2021. 


\section{Publish your work in this journal}

Clinical, Cosmetic and Investigational Dermatology is an international, peer-reviewed, open access, online journal that focuses on the latest clinical and experimental research in all aspects of skin disease and cosmetic interventions. This journal is indexed on CAS.
The manuscript management system is completely online and includes a very quick and fair peer-review system, which is all easy to use. Visit http://www.dovepress.com/testimonials.php to read real quotes from published authors.

Submit your manuscript here: https://www.dovepress.com/clinical-cosmetic-and-investigational-dermatology-journal 